\title{
Aplicação de Dessecantes na Cultura de Soj A: TeOr de Umidade nas Sementes e Biomassa nas Plantas ${ }^{1}$
}

\author{
Application Dissecants in Soybean: Degree of Humidity in the Plant's Seeds and Biomass
}

LACERDA, A.L.S. ${ }^{2}$, LAZARINI, E. ${ }^{3}$, SÁ, M.E. ${ }^{3}$ e WALTER FILHO, V.V. ${ }^{4}$

\begin{abstract}
RESUMO - Os objetivos deste trabalho foram avaliar a eficácia dos dessecantes e determinar a melhor época de aplicação na cultura de soja. O delineamento experimental utilizado foi em blocos casualizados, estando os tratamentos dispostos em esquema fatorial 3x3 e 4x4 de produtos (dessecantes) e épocas de aplicação, nos anos agrícolas 1996/97 e 1997/98, respectivamente. Os dessecantes utilizados foram: paraquat, diquat e paraquat + diquat em 1996/97 e paraquat, diquat, paraquat + diquat e glufosinato de amônio em 1997/98, respectivamente nas dosagens de 0,4, 0,3 e 0,2 + 0,15; e 0,4, 0,3, 0,2 + 0,15 e 0,4 kg i.a. ha ${ }^{-1}$. Como épocas, foram realizadas três aplicações em 1996/97 e quatro em 1997/98, com intervalos de cinco dias a partir do estádio $\mathrm{R}_{6}$. Após análise e interpretação dos resultados, concluiu-se que os dessecantes foram eficazes na dessecação e que o teor de umidade das sementes entre 50 e 60\%, as plantas com baixa incidência de vagens amarelas e marrons e a relação peso de biomassa verde de vagens/biomassa verde total de cerca de 0,5 foram características marcantes na determinação da melhor época de aplicação dos dessecantes.
\end{abstract}

Palavras-chave: Glycine max, dessecação, diquat, paraquat, glufosinato de amônio.

\begin{abstract}
The objectives of this work were to evaluate dissecant efficiency and determine the best application time for soybean crop. The experimental design was randomized blocks in factorial schemes $3 \times 3$ and $4 \times 4$ (dissecants $x$ application time), in 1996/1997 and 1997/1998, respectively. The dissecants applied were: paraquat, diquat and paraquat + diquat in 1996/97 and paraquat, diquat, paraquat + diquat and ammonium glufosinate in 1997/1998, respectively, in the following doses: $0.4 ; 0.3$ and $0.2+0.15$ and $0.4 ; 0.3 ; 0.2+0.15$ and $0.4 \mathrm{~kg}$ a.i. ha $\mathrm{a}^{-1}$ Three application times were used in 1996/1997 and four in 1997/1998, with intervals of five days starting from stage $R_{6}$. Analysis and interpretation of the results allowed to conclude that the dissecants were efficient and that seed moisture between 50 and 60\%, plants with low incidence of yellow and brown beans and the relation green biomass weight/total green biomass weight of the plants around 0.5 were the main characteristics for determining the best times for dissecant application.
\end{abstract}

Key words: Glycine max, dissecation, diquat, paraquat, ammonium glufosinate.

\section{INTRODUÇÃO}

O paraquat (Reglone $\left.{ }^{\circledR}\right)$ e o diquat (Gramoxone ${ }^{\circledR}$ ) são herbicidas de contato e muito eficazes na dessecação de culturas e plantas daninhas. Inibidores do fotosistema I reduzem drasticamente o teor de água da biomassa verde das plantas, podendo ocasionar antecipação da colheita. Uma das justificativas para a aplicação desses produtos na cultura de soja é a vulnerabilidade das sementes. Estas, quando expostas às condições climáticas adversas, ou seja, altas temperaturas e precipitações na fase final do ciclo da cultura, podem ocasionar prejuízos no rendimento de grãos devido à deterioração provocada pelo seu alto teor de óleo. A desocupação antecipada da área para uma nova cultura (safrinha), contribuindo

Recebido para publicação em 22.2.2002 e na forma revisada em 12.12.2003.

2 Eng.-Agrônomo, M.S. Doutorando em Fitotecnia no Dep. de Produção Vegetal da Escola Superior de Agricultura "Luiz de Queiroz" - ESALQ/USP, Rua Padre Francisco de Abreu Sampaio, 269, 13030-350 Campinas-SP. ${ }^{3}$ Professor do Dep. de Fitotecnia, Economia e Sociologia Rural - FEIS/UNESP, Av. Brasil, 56, 15385-000 Ilha Solteira-SP. ${ }^{4}$ Professor do Dep. de Matemática FEIS/UNESP, <alslacer@bol.com.br>. 
com a renda do produtor, a retenção foliar, o acamamento das plantas de soja e os fluxos de emergência tardios de plantas daninhas também podem justificar a dessecação no ciclo final da cultura.

A época de aplicação é outro fator importante para evitar perdas no rendimento; o melhor momento é quando a soja acumula o máximo de biomassa seca - denomina-se este ponto como de maturidade fisiológica da semente $\left(R_{7}\right)$. Segundo Tekrony et al. (1980), nesse momento a semente torna-se independente da planta e o teor de umidade nas sementes passa a ser controlado pelas condições ambientais, sem participação de atividade fisiológica da planta ou da semente.

De acordo com Burris (1973), o teor de umidade nas sementes de soja, inicialmente, por ocasião da sua fertilização é de aproximadamente $90 \%$, ocorrendo em seguida uma redução de 70\%; posteriormente, durante quase todo o período de acúmulo do peso da biomassa seca, o teor de umidade diminui lentamente. Quando chega o ponto de maturidade fisiológica $\left(R_{7}\right)$, as sementes apresentam 50 a $60 \%$ de umidade, o que impossibilita sua colheita, pois, conforme a EMBRAPA (1998), a colheita da soja deve ser iniciada tão logo atinja teor de umidade entre 13 e 15\% - nessas condições, têm-se minimizado os problemas de danos mecânicos e perdas na colheita. Hamer e Peske (1997) afirmam que a colheita deve ser realizada com teor de umidade nas sementes entre 14 e $18 \%$.

Os objetivos do presente trabalho foram avaliar a eficácia dos dessecantes e determinar a melhor época de aplicação na cultura de soja por meio do monitoramento do teor de umidade nas sementes e da quantidade de biomassa seca nas plantas.

\section{MATERIAL E MÉTODOS}

Os ensaios foram instalados na área experimental da Fazenda de Ensino e Pesquisa (FEP) pertencente à Faculdade de Engenharia de Ilha Solteira - UNESP, localizada no município de Selvíria-MS, apresentando como coordenadas geográficas $51^{\circ} 22 \mathrm{~W}$ e $20^{\circ} 22^{\prime} \mathrm{S}$ e aproximadamente $335 \mathrm{~m}$ de altitude, $1.370 \mathrm{~mm}$ de precipitação e $23,5^{\circ} \mathrm{C}$ de temperatura média anual. O solo é do tipo Latossolo Vermelho-
Escuro argiloso e foi preparado de maneira convencional. A adubação química utilizada foi de $300 \mathrm{~kg} \mathrm{ha}^{-1}$ da fórmula 04-30-10 no primeiro ano e $300 \mathrm{~kg} \mathrm{ha}^{-1}$ da fórmula 02-20-20 no segundo ano. As sementes foram tratadas com o fungicida Captan 750 TS (160 g.p.c. $100 \mathrm{~kg}^{-1}$ de sementes) e, a seguir, inoculadas com Bradyrhizobium japonicum (400 g de inoculante turfoso por $50 \mathrm{~kg}$ de sementes).

As semeaduras e a emergência ocorreram em 20/11/96 e 27/11/96, 04/12/97 e 10/12/ 97 , respectivamente. O manejo da cultura foi realizado de acordo com as recomendações da EMBRAPA (1996).

O delineamento experimental utilizado foi em blocos casualizados, com quatro repetições. Os tratamentos utilizados foram dispostos em esquema fatorial 3x3 e 4x4 (dessecantes e épocas de aplicação), nos anos agrícolas 1996/ 97 e 1997/98, respectivamente. As parcelas experimentais constaram de 10 linhas de $12 \mathrm{~m}$ de comprimento, com espaçamento de $0,5 \mathrm{~m}$, considerando-se como área útil as quatro linhas centrais com $5 \mathrm{~m}$ de comprimento, desprezando-se 3,5 $\mathrm{m}$ em cada extremidade da parcela. Foram consideradas como testemunha as parcelas sem aplicação de dessecantes, colhidas quando as plantas apresentavam 95\% de vagens maduras, portanto no estádio $\mathrm{R}_{8}$. O cultivar de soja utilizado foi o IAC - 15 , recomendado para a região, segundo a EMBRAPA (1996).

Os dessecantes utilizados nos anos agrícolas 1996/97 foram: paraquat, diquat e paraquat + diaquat (mistura em tanque) nas dosagens de 0,4; 0,2; e 0,2+0,15 kg i. a. ha-1, respectivamente. Em 1997/98 utilizaram-se os mesmos dessecantes nas mesmas dosagens, sendo acrescentado o glufosinato de amônio na dosagem de $0,4 \mathrm{~kg}$ i. a. ha ${ }^{-1}$. Os produtos comerciais usados foram o Gramoxone ${ }^{\circledR}$, Reglone ${ }^{\circledR}$ e Finale ${ }^{\circledR}$. Os intervalos de aplicação foram de cinco dias. Foram realizadas três aplicações em 1997, nas seguintes datas: 26/ 02, 03/03 e 08/03, ou seja, aos 98, 103 e 108 dias após a emergência, quando a soja apresentava 90, 9 e 1\%; 97, 20 e 48\%; 0, 1 e 99\% de vagens verdes, amarelas e marrons, respectivamente. No ano de 1998 foram realizadas quatro aplicações, nas seguintes datas: 05/03, 10/03, 15/03 e 20/03, ou seja, aos 85, 90, 95 e 100 dias após a emergência, 
com a soja apresentando 100, 0 e 0\%; 97, 3 e $0 \% ; 75,16$ e 9\%; e 18, 22 e 60\% de vagens verdes, amarelas e marrons, respectivamente. A determinação dos estádios reprodutivos $R_{6}$, $R_{7}$ e $R_{8}$ foi baseada em Fehr et al. (1971).

Os dessecantes foram aplicados mecanicamente, sempre no período da manhã, com o auxílio de um pulverizador de barra (Jacto M-12), calibrado para consumo de calda de $300 \mathrm{~L} \mathrm{ha}^{-1}$, conforme recomendação no rótulo dos dessecantes, equipado com ponta do tipo cônico vazio $\left(D_{6}\right)$ no ano agrícola $96 / 97$ e ponta do tipo leque $\left(110^{\circ}-\mathrm{SF}\right.$ - 02) no ano agrícola $97 / 98$. Utilizou-se espalhante adesivo aniônico na proporção de $12 \mathrm{~mL} 20 \mathrm{~L}^{-1}$ de calda $(0,06 \% \mathrm{v} / \mathrm{v})$ para os dessecantes paraquat, diquat e paraquat + diquat e de $20 \mathrm{~mL} 20 \mathrm{~L}^{-1}$ $(0,1 \% \mathrm{v} / \mathrm{v})$ para o glufosinato de amônio.

Para realizar as análises de variância e avaliar os efeitos dos tratamentos, utilizou-se o programa estatístico SANEST. A comparação entre médias pelo teste de Tukey, dos dados obtidos, foi efetuada quando $\mathrm{F}$ foi significativo a $5 \%$ de probabilidade.

\section{Avaliações}

Fenologia e determinação da biomassa verde e seca: foram coletadas, antes da aplicação dos dessecantes, 10 plantas seguidas em uma das linhas da área útil de cada parcela, sendo identificadas e levadas para o laboratório, onde se retiraram folhas, caule + ramos e vagens. Para determinação do estádio fenológico da soja, as vagens foram separadas em verdes, amarelas e marrons, contadas e calculadas suas porcentagens. Todas as partes foram pesadas para determinação do peso da biomassa verde e, logo após, colocadas em estufa de circulação forçada de ar a $65^{\circ} \mathrm{C}$ até atingirem peso constante, quando foram pesadas novamente, para determinação do peso de biomassa seca.

Teor de umidade das sementes: no ano agrícola 1996/97, esta avaliação foi feita imediatamente antes das aplicações dos dessecantes e após sete dias, e no ano de 1997/98, antes das aplicações, no terceiro, sétimo e décimo dias após, pela amostragem de 10 plantas aleatoriamente nas extremidades das linhas centrais de cada parcela, de onde se retiraram vagens em diferentes pontos (baixeiro, meio e ponteiro), das quais foram retiradas as sementes para determinação do teor de umidade pelo método da estufa (105 $\pm 3{ }^{\circ} \mathrm{C}$ por 24 horas), conforme metodologia indicada pela RAS (Brasil, 1992).

As Figuras 1 e 2 apresentam os dados climáticos diários durante o ciclo da cultura e também as épocas da aplicação dos dessecantes e de colheita das sementes.

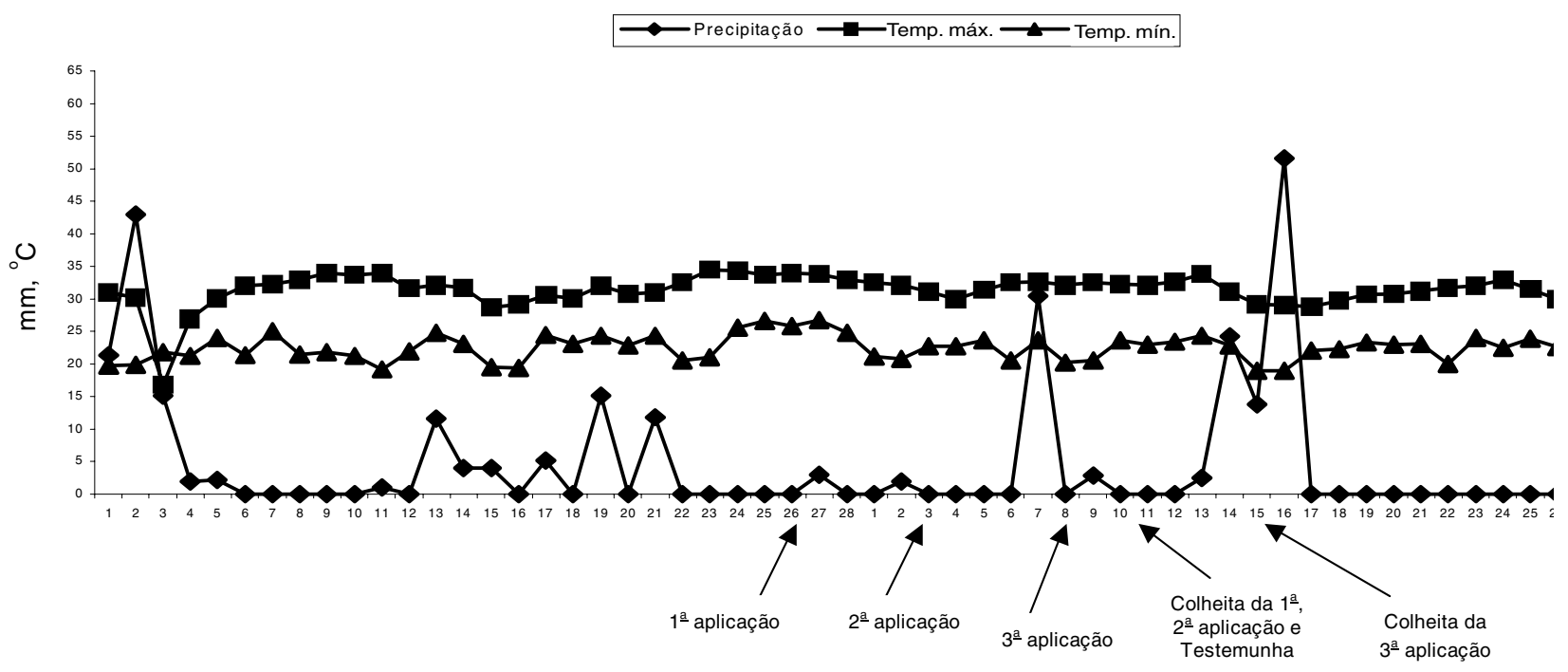

Figura 1 - Precipitação $(\mathrm{mm})$ e temperaturas máxima e mínima $\left({ }^{\circ} \mathrm{C}\right)$ registradas no posto meteorológıco da Fazenda de Ensino e Pesquisa da UNESP, nos meses de fevereiro e março de 1996. Selvíria-MS. 


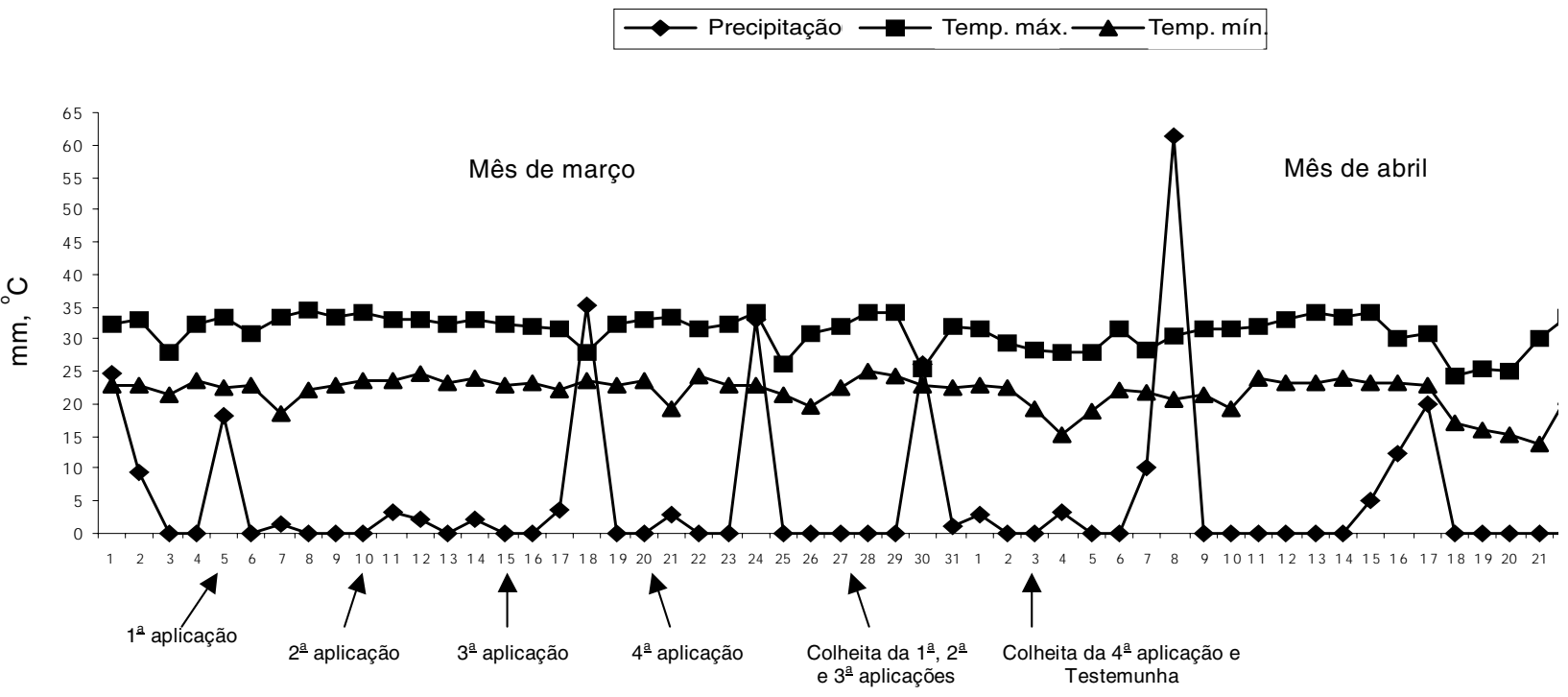

Figura 2 - Precipitação $(\mathrm{mm})$ e temperaturas máxima e mínima $\left({ }^{\circ} \mathrm{C}\right)$ registradas no posto meteorológico da Fazenda de Ensino e Pesquisa da UNESP, nos meses de março e abril de 1997. Selvíria-MS.

\section{RESULTADOS E DISCUSSÃO}

No ano agrícola 1996/97 as plantas, em média, apresentaram elevada porcentagem de vagens verdes na primeira aplicação em 26/02 (Figura 3), característica pertencente ao estádio $\mathrm{R}_{6}$, e que as plantas rapidamente atingiram o estádio $R_{8}(08 / 03)$, provavelmente devido às condições climáticas favoráveis à senescência das plantas (Figura 1).

Na Tabela 1 encontram-se os dados referentes ao peso de biomassa verde e seca das diferentes partes das plantas nas três épocas de aplicação do ano agrícola 1996/97. Verificou-se que houve diferenças significativas para o fator épocas quanto ao peso de biomassa verde de folhas, caule + ramos, vagens e total e ao peso de biomassa seca de folhas; o mesmc não ocorreu para dessecantes e a interaçãc entre épocas e dessecantes. A não-observaçãc de diferenças significativas nas partes estruturais da soja, encontradas em cada parcela demonstra a homogeneidade da cultura ne área experimental, ou seja, os dessecantes foram aplicados em alvos semelhantes. Ne primeira época de aplicação (26/02), as plantas apresentaram maior quantidade de folhas e altc teor de água (75\%). À medida que elas foram senescendo e aproximando-se do estádio $\mathrm{R}_{8}$, foram perdendo folhas e contendo menores teores de água, sendo de 69 e $23 \%$, respectivamente, para as segunda e terceira épocas de aplicação. Os teores de água nas folhas foram calculados pela relação entre as diferenças da biomassa verde e seca, dividida pela biomassa verde e multiplicada por 100 .

Apesar de não ter ocorrido diferença significativa de biomassa seca nas vagens, para o fator época, houve acúmulo máximo na segunda época de aplicação (03/03), o que provavelmente indicou ser a melhor ocasião para se fazer aplicação dos dessecantes, aliado ao fato de que, conforme observado na Tabela 1, as plantas provavelmente encontravam-se em $\mathrm{R}_{7}$. Para Potts (1971), uma semente está madura quando acumula o máximo de biomassa seca.

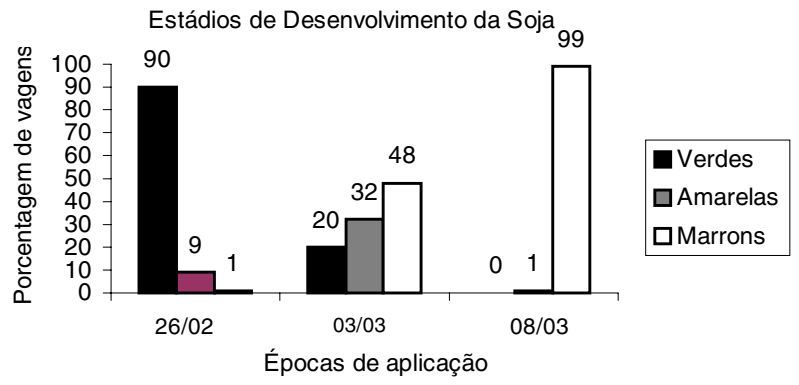

Figura 3 - Porcentagem de vagens verdes, amarelas e marrons nas diferentes épocas de aplicações dos dessecantes (ano agrícola 1996/97). 
Tabela 1 - Análises das variâncias e médias do peso da biomassa verde e seca (g por 10 plantas) de folhas, caules + ramos $(\mathrm{C}+\mathrm{R})$, vagens e total, obtidas nas parcelas antes das aplicações dos dessecantes, nas diferentes épocas avaliadas. Ano agrícola $96 / 97^{1 /}$

\begin{tabular}{|c|c|c|c|c|c|c|c|c|}
\hline \multirow{2}{*}{$\begin{array}{c}\text { Época/ } \\
\text { Dessecante }\end{array}$} & \multicolumn{4}{|c|}{ Peso da biomassa verde } & \multicolumn{4}{|c|}{ Peso da biomassa seca } \\
\hline & Folhas & $\mathrm{C}+\mathrm{R}$ & Vagens & Total & Folhas & $\mathrm{C}+\mathrm{R}$ & Vagens & Total \\
\hline $26 / 02$ & $203,1 \mathrm{a}$ & $207,8 \mathrm{a}$ & $341,1 \mathrm{a}$ & $752,0 \mathrm{a}$ & $50,3 \mathrm{a}$ & 72,3 & 118,7 & 241,3 \\
\hline $03 / 03$ & $71,1 \mathrm{~b}$ & $163,6 \mathrm{~b}$ & $228,9 \mathrm{~b}$ & $463,6 \mathrm{~b}$ & $22,2 \mathrm{~b}$ & 61,7 & 137,6 & 221,5 \\
\hline $08 / 03$ & $19,2 \mathrm{c}$ & $75,9 \mathrm{c}$ & $135,3 \mathrm{c}$ & $230,4 \mathrm{c}$ & $14,8 \mathrm{~b}$ & 58,6 & 118,4 & 191,8 \\
\hline Paraquat & 104,6 & 155,5 & 254,6 & 514,7 & 31,0 & 66,6 & 128,5 & 226,1 \\
\hline Diquat & 96,4 & 149,3 & 238,0 & 483,7 & 28,2 & 63,8 & 132,0 & 224,0 \\
\hline Paraquat + diquat & 84,5 & 135,2 & 191,4 & 411,1 & 25,2 & 56,6 & 110,0 & 191,8 \\
\hline Testemunha & 105,8 & 156,5 & 257,4 & 519,7 & 31,9 & 69,8 & 129,0 & 230,7 \\
\hline \multicolumn{9}{|c|}{ Teste F } \\
\hline Épocas $(E)$ & $78,89 * *$ & $39,47 * *$ & $18,32 * *$ & $39,10^{* *}$ & $44,64 * *$ & $3,24^{\mathrm{ns}}$ & $1,07^{\mathrm{ns}}$ & $2,46^{\text {ns }}$ \\
\hline Dessecantes (D) & $0,63^{\text {ns }}$ & $0,63^{\text {ns }}$ & $1,13^{\text {ns }}$ & $1,06^{\text {ns }}$ & $0,88^{\text {ns }}$ & $1,46^{\mathrm{ns}}$ & $0,67^{\mathrm{ns}}$ & $0,93^{\text {ns }}$ \\
\hline $\mathrm{E} * \mathrm{D}$ & $1,58^{\mathrm{ns}}$ & $0,33^{\text {ns }}$ & $0,96^{\mathrm{ns}}$ & $1,47^{\text {ns }}$ & $1,38^{\text {ns }}$ & $1,05^{\mathrm{ns}}$ & $0,83^{\text {ns }}$ & $1,09^{\text {ns }}$ \\
\hline \multicolumn{9}{|c|}{ DMS Tukey (5\%) } \\
\hline Épocas & 37,1 & 37,1 & 81,1 & 145,2 & 9,7 & 13,9 & 36,9 & 55,4 \\
\hline Dessecantes & 47,2 & 47,2 & 103,2 & 184,9 & 12,3 & 17,6 & 47,0 & 70,5 \\
\hline $\mathrm{CV}(\%)$ & 43,6 & 28,7 & 38,1 & 34,7 & 38,5 & 25,0 & 34,0 & 29,3 \\
\hline
\end{tabular}

${ }^{1 /}$ Médias seguidas da mesma letra na coluna não diferem estatisticamente entre si pelo teste de Tukey a $5 \%$ de probabilidade.

No ano agrícola 1997/98, observa-se, na Figura 4, que as aplicações ocorreram em três fases distintas de desenvolvimento da cultura, ou seja, a primeira e a segunda aplicação ocorreram com as plantas em estádio $\mathrm{R}_{6}$; a terceira, além do estádio $\mathrm{R}_{7}$; e a quarta foi realizada com as plantas próximas ao estádio $R_{8}$, pois, segundo Fehr et al. (1971), são necessários no mínimo $95 \%$ de vagens marrons para se caracterizar este estádio.

A avaliação do peso de biomassa verde e seca nas três partes das plantas amostradas nas parcelas da área experimental antes das

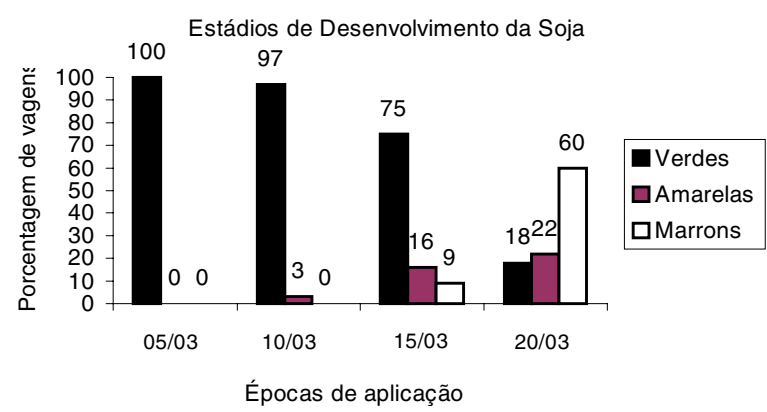

Figura 4 - Porcentagem de vagens verdes, amarelas e marrons nas diferentes épocas de aplicações dos dessecantes (ano agrícola 1997/98). aplicações dos dessecantes, nas diferentes épocas do ano de 1997/98, encontra-se na Tabela 2. A diferença significativa para o fator épocas em todas as características avaliadas, menos na biomassa seca de caule+ramos, confirma que as aplicações dos dessecantes ocorreram quando a cultura se encontrava em estádios de desenvolvimento diferentes, ou seja, $\mathrm{R}_{6}, \mathrm{R}_{7}$ e $\mathrm{R}_{8}$. Não se observou o mesmo para dessecantes, indicando a homogeneidade de desenvolvimento das plantas (novamente aplicados em alvos semelhantes), e também não houve efeito significativo da interação entre épocas e dessecantes. Nas folhas, verificou-se novamente diminuição dos valores de biomassa verde e seca à medida que avançaram as épocas de aplicação, fato esse ocorrido naturalmente, devido à perda de água e/ou queda de folhas por causa da senescência das plantas. A variável biomassa seca de vagens foi máxima na terceira época de aplicação (15/03), diferindo significativamente das aplicações anteriores, indicando talvez o melhor momento da aplicação de dessecantes e o ponto de maturidade fisiológica das sementes.

Os resultados do teor de umidade nas sementes do ano agrícola 1996/97 estão na Tabela 3. Na primeira, o período de sete

Planta Daninha, Viçosa-MG, v.21, n.3, p.427-434, 2003 
Tabela 2 - Análises das variâncias e médias do peso da biomassa verde e seca (g por 10 plantas) de folhas, caules + ramos $(\mathrm{C}+\mathrm{R})$, vagens e total, obtidas nas parcelas antes das aplicações dos dessecantes, nas diferentes épocas avaliadas. Ano agrícola $1997 / 98^{\underline{1}}$

\begin{tabular}{|c|c|c|c|c|c|c|c|c|}
\hline \multirow{2}{*}{$\begin{array}{c}\text { Época/ } \\
\text { Dessecante }\end{array}$} & \multicolumn{4}{|c|}{ Peso da biomassa verde } & \multicolumn{4}{|c|}{ Peso da biomassa seca } \\
\hline & Folhas & $\mathrm{C}+\mathrm{R}$ & Vagens & Total & Folhas & $\mathrm{C}+\mathrm{R}$ & Vagens & Total \\
\hline $05 / 03$ & $273,8 \mathrm{a}$ & $312,6 \mathrm{a}$ & $382,6 \mathrm{bc}$ & $969,0 \mathrm{a}$ & 88,7 a & 104,7 & $122,7 \mathrm{~b}$ & $316,2 \mathrm{ab}$ \\
\hline $10 / 03$ & $268,2 \mathrm{a}$ & $274,1 \mathrm{ab}$ & $400,0 \mathrm{~b}$ & $942,3 \mathrm{a}$ & $72,4 \mathrm{~b}$ & 92,0 & $125,0 \mathrm{~b}$ & $289,4 \mathrm{ab}$ \\
\hline $15 / 03$ & $225,5 \mathrm{a}$ & 326,6 a & $501,0 \mathrm{a}$ & $1053,1 \mathrm{a}$ & $58,7 \mathrm{~b}$ & 102,5 & $168,3 \mathrm{a}$ & 329,6 a \\
\hline $20 / 03$ & $66,3 \mathrm{~b}$ & $241,7 \mathrm{~b}$ & $302,3 \mathrm{c}$ & $610,2 \mathrm{~b}$ & $21,7 \mathrm{c}$ & 88,0 & $153,8 \mathrm{ab}$ & $263,5 \mathrm{~b}$ \\
\hline Paraquat & 217,7 & 295,0 & 418,9 & 931,6 & 64,1 & 96,6 & 146,0 & 306,7 \\
\hline Diquat & 239,1 & 297,9 & 404,1 & 941,1 & 61,5 & 98,4 & 147,0 & 306,9 \\
\hline Paraquat + diquat & 195,8 & 274,3 & 366,9 & 837,0 & 58,7 & 96,0 & 134,4 & 289,1 \\
\hline Gluf. de amônio & 209,5 & 291,4 & 411,0 & 911,8 & 63,0 & 96,3 & 144,0 & 303,3 \\
\hline Testemunha & 180,0 & 285,0 & 381,6 & 846,7 & 54,7 & 96,7 & 140,8 & 292,3 \\
\hline \multicolumn{9}{|c|}{ Teste F } \\
\hline Épocas (E) & $30,45^{* *}$ & $5,34 * *$ & $10,56^{* *}$ & $11,87 * *$ & $46,20 * *$ & $2,79^{\text {ns }}$ & $6,13 * *$ & $3,03 *$ \\
\hline Dessecantes (D) & $0,77^{\mathrm{ns}}$ & $0,25^{\text {ns }}$ & $0,59^{\text {ns }}$ & $0,59^{\text {ns }}$ & $0,64^{\text {ns }}$ & $0,03^{\mathrm{ns}}$ & $0,25^{\mathrm{ns}}$ & $0,20^{\text {ns }}$ \\
\hline $\mathrm{E} * \mathrm{D}$ & $1,14^{\mathrm{ns}}$ & $1,30^{\mathrm{ns}}$ & $1,47^{\text {ns }}$ & $1,37^{\mathrm{ns}}$ & $1,24^{\text {ns }}$ & $1,24^{\mathrm{ns}}$ & $1,08^{\mathrm{ns}}$ & $1,31^{\text {ns }}$ \\
\hline \multicolumn{9}{|c|}{ DMS Tukey (5\%) } \\
\hline Épocas & 64,1 & 62,3 & 94,2 & 211,8 & 15,7 & 18,2 & 33,7 & 63,1 \\
\hline Dessecantes & 76,3 & 74,2 & 112,1 & 252,1 & 18,7 & 21,7 & 40,2 & 75,0 \\
\hline CV (\%) & 43,6 & 28,7 & 38,1 & 34,7 & 38,5 & 25,0 & 28,3 & 25,1 \\
\hline
\end{tabular}

${ }^{1 /}$ Médias seguidas da mesma letra na coluna não diferem estatisticamente entre si pelo teste de Tukey a 5\% de probabilidade.

dias não foi suficiente para as sementes atingirem a faixa ideal de colheita, devido ao seu elevado teor de água $(60,4 \%)$, embora se tenha observado acentuada redução dessa umidade (para 20,9\%). Na segunda e terceira épocas de aplicação, as sementes apresentavam teores de umidade de 45,7 e 24,9\%, e, após sete dias, 11,0 e $17,9 \%$, respectivamente. A faixa de 13 a $15 \%$ foi atingida antes da segunda aplicação. Na terceira aplicação obteve-se aumento do teor de umidade nas sementes devido à ocorrência de chuvas no período em que foram coletadas as amostras para verificação da umidade (Figura 1). Também Bovey et al. (1975) observaram maiores taxas de secagem quando as sementes apresentavam aproximadamente $45 \%$ de teor de umidade.

Os teores de umidade nas sementes obtidos por amostragens feitas nas parcelas antes da aplicação dos dessecantes não foram diferentes significativamente (Tabela 3). Assim, nenhum dessecante foi favorecido ou desfavorecido pelo fato de as sementes possuírem menor ou maior quantidade de água, podendo-se dizer que os dessecantes foram eficazes; contudo, apenas a mistura paraquat + diquat foi diferente significativamente em relação à testemunha.

Tabela 3 - Análises das variâncias e do teor de umidade (\%) nas sementes amostradas antes e sete dias após a aplicação dos dessecantes paraquat, diquat e paraquat + diquat em três épocas de aplicação. Ano agrícola 1996/97 ${ }^{\prime}$

\begin{tabular}{|l|c|c|}
\hline \multirow{2}{*}{ Época/Dessecante } & Antes & 7 Dias \\
\cline { 2 - 3 } & \multicolumn{2}{|c|}{$(\%)$} \\
\hline $26 / 02$ & $60,4 \mathrm{a}$ & $20,9 \mathrm{a}$ \\
\hline $03 / 03$ & $45,7 \mathrm{~b}$ & $11,0 \mathrm{~b}$ \\
\hline $08 / 03$ & $24,9 \mathrm{c}$ & $17,9 \mathrm{a}$ \\
\hline Paraquat & 44,6 & $15,9 \mathrm{ab}$ \\
\hline Diquat & 44,2 & $15,7 \mathrm{ab}$ \\
\hline Paraquat + diquat & 44,1 & $15,1 \mathrm{~b}$ \\
\hline Testemunha & 41,8 & $19,6 \mathrm{a}$ \\
\hline \multicolumn{3}{|c|}{ Teste F } \\
\hline Épocas (E) & $655,68^{* *}$ & $24,64^{* *}$ \\
\hline Dessecantes (D) & $2,46^{\mathrm{n}}$ & $2,96^{*}$ \\
\hline E* D & $1,57^{\text {ns }}$ & $3,73^{* *}$ \\
\hline \multicolumn{3}{|c|}{ DMS Tukey $(5 \%)$} \\
\hline Épocas & 2,4 & 3,6 \\
\hline Dessecantes & 3,1 & 4,5 \\
\hline CV $(\%)$ & 6,4 & 24,7 \\
\hline
\end{tabular}

${ }^{1 /}$ Médias seguidas da mesma letra na coluna não diferem estatisticamente entre si pelo teste de Tukey a $5 \%$ de probabilidade. 
O desdobramento da interação entre épocas e dessecantes (Tabela 4) mostrou que sete dias após a primeira aplicação todos os dessecantes proporcionaram grande redução do teor de água nas sementes, diferindo significativamente da testemunha. O grau de umidade nas parcelas, onde houve aplicação dos dessecantes, foi próximo ao ideal para colheita, mostrando que neste estádio de desenvolvimento das plantas os dessecantes foram eficazes na desidratação das sementes.

Tabela 4 - Desdobramento da interação significativa entre épocas e dessecantes no teor de umidade das sementes (\%) aos sete dias após aplicação dos dessecantes. Ano agrícola $1996 / 97^{1 /}$

\begin{tabular}{|l|c|c|c|}
\hline \multirow{2}{*}{ Dessecante } & \multicolumn{3}{|c|}{ Época de aplicação } \\
\cline { 2 - 4 } & $26 / 02$ & $03 / 03$ & $08 / 03$ \\
\hline Paraquat & $17,6 \mathrm{Aab}$ & $11,2 \mathrm{~b}$ & $18,8 \mathrm{a}$ \\
\hline Diquat & $18,7 \mathrm{Aa}$ & $10,8 \mathrm{~b}$ & $17,7 \mathrm{a}$ \\
\hline Paraquat + diquat & $16,5 \mathrm{~A}$ & 11,0 & 17,9 \\
\hline Testemunha & $30,7 \mathrm{Ba}$ & $10,8 \mathrm{c}$ & $17,3 \mathrm{~b}$ \\
\hline \multicolumn{3}{|c|}{} \\
DMS: Época dentro de dessecantes $=7,2$ \\
Dessecante dentro de épocas $=6,5$ \\
\hline
\end{tabular}

1/ Médias seguidas pela mesma letra minúscula, na linha, e pela mesma letra maiúscula, na coluna, não diferem estatisticamente entre si pelo teste de Tukey a 5\% de probabilidade.

O aumento no teor de umidade nas sementes em 15/03 (sete dias após a terceira aplicação) se deveu às chuvas ocorridas em dias anteriores à avaliação, conforme ilustra a Figura 1, pois a testemunha também apresentava em 10/03 (sete dias após a segunda aplicação) $10,8 \%$ de umidade, indicando o momento de colheita nas parcelas para todas as aplicações. Isso ocorreu para a primeira e segunda aplicações e a testemunha, e não para a terceira aplicação, em razão de se aguardar o período de carência dos dessecantes aplicados.

Na Tabela 5 estão os dados do teor de umidade nas sementes antes, 3, 7 e 10 dias após aplicação dos dessecantes, no ano agrícola $1997 / 98$. Nas três primeiras aplicações as sementes continham teor de água superior a $60 \%$ e 10 dias após, apenas na terceira aplicação obteve-se teor próximo ao limite recomendado para início da colheita; porém, aos sete dias após a quarta aplicação o teor de água foi suficiente para iniciar a colheita.

Deve-se ressaltar que na primeira aplicação foi registrado um período de 22 dias entre
Tabela 5 - Análises das variâncias e do teor de umidade (\%) nas sementes amostradas antes, 3, 7 e 10 dias após aplicação dos dessecantes paraquat, diquat, paraquat + diquat e glufosinato de amônio, aplicados em quatro épocas. Ano agrícola 1997/98 ${ }^{-1}$

\begin{tabular}{|l|c|c|c|c|}
\hline \multirow{2}{*}{ Época/Dessecante } & Antes & 3 dias & 7 dias & 10 dias \\
\cline { 2 - 5 } & \multicolumn{4}{|c|}{$(\%)$} \\
\hline $05 / 03$ & $67,3 \mathrm{a}$ & $67,9 \mathrm{a}$ & $59,0 \mathrm{a}$ & $49,1 \mathrm{a}$ \\
\hline $10 / 03$ & $66,7 \mathrm{a}$ & $61,4 \mathrm{~b}$ & $39,3 \mathrm{~b}$ & $32,3 \mathrm{~b}$ \\
\hline $15 / 03$ & $60,3 \mathrm{~b}$ & $52,1 \mathrm{c}$ & $32,3 \mathrm{c}$ & $15,4 \mathrm{c}$ \\
\hline $20 / 03$ & $47,9 \mathrm{c}$ & $37,5 \mathrm{~d}$ & $15,0 \mathrm{~d}$ & $19,2 \mathrm{c}$ \\
\hline Paraquat & 60,2 & 55,8 & $34,2 \mathrm{~b}$ & $26,3 \mathrm{~b}$ \\
\hline Diquat & 60,4 & 53,5 & $34,3 \mathrm{~b}$ & $25,3 \mathrm{~b}$ \\
\hline Paraquat + diquat & 60,8 & 54,7 & $33,6 \mathrm{~b}$ & $28,9 \mathrm{~b}$ \\
\hline Gluf. de amônio & 61,0 & 53,5 & $35,6 \mathrm{~b}$ & $28,2 \mathrm{~b}$ \\
\hline Testemunha & 60,2 & 56,0 & $44,2 \mathrm{a}$ & $36,3 \mathrm{a}$ \\
\hline \multicolumn{5}{|c|}{ Teste de F } \\
\hline Épocas (E) & $108,91^{* *}$ & $120,27 * *$ & $181,21^{* *}$ & $130,6^{* *}$ \\
\hline Dessecantes (D) & $0,14^{\mathrm{ns}}$ & $0,80^{\mathrm{ns}}$ & $8,60^{* *}$ & $8,5^{* *}$ \\
\hline E*D & $0,58^{\mathrm{ns}}$ & $1,02^{\mathrm{ns}}$ & $1,97 *$ & $3,9^{* *}$ \\
\hline \multicolumn{5}{|c|}{ DMS Tukey $(5 \%)$} \\
\hline Épocas & 3,2 & 4,5 & 5,1 & 5,0 \\
\hline Dessecantes & 3,8 & 5,4 & 6,0 & 5,9 \\
\hline CV (\%) & 6,4 & 9,8 & 16,6 & 20,5 \\
\hline
\end{tabular}

${ }^{1 /}$ Médias seguidas da mesma letra na coluna não diferem estatisticamente entre si pelo teste de Tukey a $5 \%$ de probabilidade.

aplicação e colheita (Figura 2), que foi considerado longo, evidenciando ser este um momento inadequado (estádio de desenvolvimento da planta) para aplicação de dessecantes. Para a terceira aplicação esse período foi de apenas 12 dias, indicando ser este o mais recomendado para aplicação de dessecantes.

Igualmente ao ano anterior, não havia diferença significativa nos teores de umidade nas sementes em plantas amostradas dias antes das aplicações dos produtos. No sétimo e décimo dias após aplicação, os dessecantes ocasionaram queda significativa nos teores de umidade, quando comparado com a testemunha. Isso demonstra a grande eficácia dos dessecantes testados quanto ao processo de desidratação das sementes, concordando com Durigan (1980) e Lacerda et al. (2001).

Na Tabela 6 verificou-se que após sete dias da primeira aplicação ainda foi detectado elevado teor de água nas sementes, cujos valores foram bastantes diferentes dos observados sete dias após a quarta aplicação. A elevada umidade nas sementes, a grande quantidade 
de folhas e a intensa atividade metabólica da planta podem ter contribuído para a demora da perda de água. No entanto, na segunda e terceira aplicações ocorreu maior redução do teor de água nas sementes, mas não suficiente para o início da colheita, como ocorreu na quarta aplicação. Quanto à eficácia dos dessecantes, o paraquat, aplicado sozinho ou em mistura com o diquat, na primeira época de aplicação (05/03), diferenciou-se significativamente da testemunha. Na segunda e terceira aplicações, todos os dessecantes proporcionaram valores menores e significativos em relação à testemunha, com destaque para mistura no tanque de paraquat e diquat, que na terceira aplicação diferenciou-se significativamente dos demais tratamentos.

Na Tabela 7 encontram-se os resultados da porcentagem de umidade das sementes aos 10 dias após aplicação dos dessecantes, nas diferentes épocas. A época em que ocorreu a terceira aplicação foi a mais adequada, pois o teor de umidade nas sementes estava dentro da faixa recomendada de colheita; os maiores valores observados na quarta aplicação se deveram às chuvas ocorridas no dia da realização das amostragens (Figura 2).

Neste trabalho, concluiu-se que os dessecantes paraquat e diquat e a mistura paraquat+diquat e glufosinato de amônio foram eficazes na perda de umidade das sementes de soja e que o período ideal para aplicação dos dessecantes na cultura da soja foi muito curto. A umidade das sementes entre 50 e $60 \%$, a razão de cerca de 0,5 o valor entre o peso de biomassa verde de vagens e o peso de biomassa

Tabela 6 - Desdobramento da interação significativa entre épocas e dessecantes no teor de umidade das sementes (\%) aos sete dias após aplicação dos dessecantes. Ano agrícola $1997 / 98^{1 /}$

\begin{tabular}{|l|c|c|c|c|}
\hline \multirow{2}{*}{ Dessecante } & \multicolumn{5}{|c|}{ Época de aplicação } \\
\cline { 2 - 5 } & $05 / 03$ & $10 / 03$ & $15 / 03$ & $20 / 03$ \\
\hline Paraquat & $55 \mathrm{BCa}$ & $35 \mathrm{Bb}$ & $32 \mathrm{~B} \mathrm{~b}$ & $15 \mathrm{c}$ \\
\hline Diquat & $60 \mathrm{ABa}$ & $30 \mathrm{Bb}$ & $34 \mathrm{~B} \mathrm{~b}$ & $14 \mathrm{c}$ \\
\hline Paraquat + diquat & $54 \mathrm{C}$ a & $40 \mathrm{Bb}$ & $26 \mathrm{C} \mathrm{c}$ & $14 \mathrm{~d}$ \\
\hline Gluf. de amônio & $61 \mathrm{~A} \mathrm{a}$ & $38 \mathrm{Bb}$ & $30 \mathrm{BCb}$ & $14 \mathrm{c}$ \\
\hline Testemunha & $65 \mathrm{~A} \mathrm{a}$ & $54 \mathrm{Aa}$ & $40 \mathrm{~A} \mathrm{~b}$ & $18 \mathrm{c}$ \\
\hline \multicolumn{4}{|r|}{$\begin{array}{r}\text { DMS: Época dentro de dessecantes = 6 } \\
\text { Dessecante dentro de épocas }=12\end{array}$} \\
\hline
\end{tabular}

1/ Médias seguidas pela mesma letra minúscula, na linha, e pela mesma letra maiúscula, na coluna, não diferem estatisticamente entre si pelo teste de Tukey a 5\% de probabilidade.
Tabela 7 - Desdobramento da interação significativa entre épocas e dessecantes no teor de umidade nas sementes (\%) aos 10 dias após aplicação dos dessecantes. Ano agrícola $1997 / 98^{1 /}$

\begin{tabular}{|l|c|c|c|c|}
\hline \multirow{2}{*}{ Dessecante } & \multicolumn{5}{|c|}{ Época de aplicação } \\
\cline { 2 - 5 } & $05 / 03$ & $10 / 03$ & $15 / 03$ & $20 / 03$ \\
\hline Paraquat & $42 \mathrm{~B}$ a & $27 \mathrm{BCb}$ & $18 \mathrm{~b}$ & $19 \mathrm{~b}$ \\
\hline Diquat & $47 \mathrm{ABa}$ & $20 \mathrm{C}$ b & $14 \mathrm{~b}$ & $19 \mathrm{~b}$ \\
\hline Paraquat + diquat & $46 \mathrm{~B}$ a & $37 \mathrm{~B}$ a & $10 \mathrm{~b}$ & $19 \mathrm{~b}$ \\
\hline Gluf. de amônio & $53 \mathrm{ABa}$ & $27 \mathrm{BCb}$ & $14 \mathrm{c}$ & $19 \mathrm{bc}$ \\
\hline Testemunha & $58 \mathrm{~A}$ a & $50 \mathrm{~A}$ a & $18 \mathrm{~b}$ & $19 \mathrm{~b}$ \\
\hline \multicolumn{5}{|r|}{ DMS: Época dentro de dessecantes = 11 } \\
Dessecante dentro de épocas = 12 \\
\hline
\end{tabular}

1/ As médias seguidas pela mesma letra minúscula, na linha, e pela mesma letra maiúscula, na coluna, não diferem estatisticamente entre si pelo teste de Tukey a 5\% de probabilidade.

verde total e o início de senescência das plantas com baixa incidência de vagens amarelas e marrons foram características marcantes na determinação desse período.

\section{AGRADECIMENTOS}

À FAPESP, pelo apoio financeiro.

\section{LITERATURA CITADA}

BOVEY, R. W.; MILLER, F. B.; BOUR, J. R. Pre-harvest desication of grain sorghum with glyphosate. Agron. J., v. 67, p. $618-21,1975$.

BURRIS, J. S. Effect of seed maturation and plant population on soybeans seed quality. Agron. J., v. 65, p. $440-441,1973$.

DURIGAN, J. Aplicação em pré-colheita, de dessecante em duas cultivares de soja (Glycine max (L.) Merril). I - Efeitos imediatos sobre a germinação e produção de sementes.

Planta Daninha, v. 3, p. 108-115, 1980.

FEHR, W. E. et al. Stage of development descriptons for soybeans, Glycine $\max ($ L.) Merrill. Crop Sci., v. 11, p. 929-931, 1971.

HAMER, E.; PESKE, S. T. Colheita de sementes de soja com alto teor de umidade: I. Qualidade física. Rev. Bras. Sem., v. 19, p. 106-110, 1997.

LACERDA, A. L. S. et al. Aplicação de dessecantes na cultura de soja: antecipação da colheita e produção de sementes. Planta Daninha, v. 19, p. 381-390, 2001.

POTTS, H. C. Seeds: development, struture, function. Misssissipi State University, 1971. p. 37-51.

TEKRONY, D. M.; EGLI, D. B.; PHILLIPS, A. D. Effect of field weathering on the viability and vigor of soybean seed. Agron. J., v. 72, p. 749-753, 1980. 